\title{
Ellagic Acid Controls Cell Proliferation and Induces Apoptosis in Breast Cancer Cells via Inhibition of Cyclin-Dependent Kinase 6
}

\author{
Mohd Yousuf ${ }^{1}$, Anas Shamsi ${ }^{2}{ }^{(D}$, Parvez Khan ${ }^{2}{ }^{\oplus}$, Mohd Shahbaaz ${ }^{3,4}$, Mohamed F. AlAjmi ${ }^{5}$, \\ Afzal Hussain ${ }^{5}{ }^{\oplus}$, Gulam Mustafa Hassan ${ }^{6}$, Asimul Islam ${ }^{2}{ }^{\circledR}$, Qazi Mohd Rizwanul Haque ${ }^{1}$ \\ and Md. Imtaiyaz Hassan $2, *(\mathbb{D})$ \\ 1 Microbiology Research Laboratory, Department of Biosciences, Jamia Millia Islamia, Jamia Nagar, New Delhi \\ 110025, India; yousufbiochem@gmail.com (M.Y.); qhaque@jmi.ac.in (Q.M.R.H.) \\ 2 Centre for Interdisciplinary Research in Basic Sciences, Jamia Millia Islamia, Jamia Nagar, New Delhi 110025, \\ India; anas.shamsi18@gmail.com (A.S.); parvezynr@gmail.com (P.K.); aislam@jmi.ac.in (A.I.) \\ 3 South African Medical Research Council Bioinformatics Unit, South African National Bioinformatics \\ Institute, University of the Western Cape, Private Bag X17, Bellville, Cape Town 7535, South Africa; \\ mohammed.shahbaaz@gmail.com \\ 4 Laboratory of Computational Modeling of Drugs, South Ural State University, 76 Lenin Prospekt, 454080 \\ Chelyabinsk, Russia \\ 5 Department of Pharmacognosy, College of Pharmacy, King Saud University, Riyadh 11451, Saudi Arabia; \\ malajmii@ksu.edu.sa (M.F.A.); afzal.hussain.amu@gmail.com (A.H.) \\ 6 Department of Biochemistry, College of Medicine, Prince Sattam Bin Abdulaziz University, P.O. Box 173, \\ Al-Kharj 11942, Saudi Arabia; mgulam@gmail.com \\ * Correspondence: mihassan@jmi.ac.in
}

Received: 7 April 2020; Accepted: 24 April 2020; Published: 15 May 2020

\begin{abstract}
Cyclin-Dependent Kinase 6 (CDK6) plays an important role in cancer progression, and thus, it is considered as an attractive drug target in anticancer therapeutics. This study presents an evaluation of dietary phytochemicals, capsaicin, tocopherol, rosmarinic acid, ursolic acid, ellagic acid (EA), limonene, caffeic acid, and ferulic acid for their potential to inhibit the activity of CDK6. Molecular docking and fluorescence binding studies revealed appreciable binding affinities of these compounds to the CDK6. Among them, EA shows the highest binding affinity for CDK6, and thus a molecular dynamics simulation study of $200 \mathrm{~ns}$ was performed to get deeper insights into the binding mechanism and stability of the CDK6-EA complex. Fluorescence binding studies revealed that EA binds to the CDK6 with a binding constant of $K=10^{7} \mathrm{M}^{-1}$ and subsequently inhibits its enzyme activity with an $\mathrm{IC}_{50}$ value of $3.053 \mu \mathrm{M}$. Analysis of thermodynamic parameters of CDK6-EA complex formation suggested a hydrophobic interaction driven process. The treatment of EA decreases the colonization of cancer cells and induces apoptosis. Moreover, the expression of CDK6 has been downregulated in EA-treated human breast cancer cell lines. In conclusion, this study establishes EA as a potent CDK6 inhibitor that can be further evaluated in CDK6 directed anticancer therapies.
\end{abstract}

Keywords: cyclin-dependent kinase 6; natural products; ellagic acid; molecular dynamics simulation; kinase inhibitor; drug design and discovery; anticancer therapy

\section{Introduction}

Pathological stages of cancer cells are characterized by dysregulated cell proliferation, increased cell survival ability, loss of differentiation, accumulation of genetic mutation, and alteration in the metabolic pathways [1]. Uncontrolled cell division and alteration in metabolism are major hallmarks 
of cancer [2]. Cancer therapeutics generally involves the identification of potential targets that play a direct or indirect role in the cell division and regulation of cell metabolism. Protein kinases regulate $>80 \%$ of cellular pathways namely cell cycle progression, transcription, DNA repair, and metabolic events in different signaling cascades through phosphorylation/dephosphorylation and thus used as a potential drug target in cancer therapy [3].

Cyclin-dependent kinases (CDKs) belongs to serine/threonine-protein kinases and plays an important role in cell cycle progression [4]. The catalytic activities of CDKs are modulated by their interactions with cyclins and CDK inhibitors (CKIs) [5]. Every stage of the cell cycle is strictly controlled by CDKs and respective cyclins and CKIs and close cooperation between these ensure orderly progression of the cell cycle [6]. Based on the sequence similarity of the kinase domain, CDKs are categorized as a member of the CMGC group of kinases [7]. CDK6 gene is located on chromosome 7q21.2, encodes a 326 amino acids monomeric protein [8], which is involved in the regulation of key metabolism and cell cycle [9]. CDK6 and cyclin D is responsible for G1 to $S$ phase transition during the cell division. Retinoblastoma (RB), a tumor suppressor, plays a switching role in the cell cycle [10]. E2F is an evolutionarily conserved family of factors that control cell cycle and significantly contributes in tumor development [6]. CDK6 is involved in the (RB)-E2F signaling and subsequently cancer progression. Uncontrolled regulation of the cyclin D-CDK4/6-INK4-RB pathway is observed in cancer resulted from an uncontrolled cell cycle and cell growth [11]. CDK6 regulates glucose metabolism by inhibiting the activity of phosphofructokinase (PFK) and pyruvate kinase (PKM) of glycolysis through phosphorylation and subsequently reduces the production of reactive oxygen species (ROS) in cells [9]. ROS are very toxic to a cell and cause apoptosis. Nonselective CDK inhibitors failed in the clinical trials due to their toxic effect on non-cancer cells. Thus, the identification of a selective CDK-6 inhibitor may be used as therapeutic targeting of cancer cell growth and metabolic alterations [2,9].

Flavonoids are generally present in different parts of plants and are of great clinical significance [12,13]. These phytoconstituents target several pathways, affect glucose homeostasis, and control cell growth. For the past few decades, phytoconstituents of medicinal plants have been extensively used for the treatment of cancer with minimal side effects. Plant-derived formulations and phytochemicals are extensively used to manage different diseases [14]. In recent years, many phytoconstituents are recommended as potent kinase inhibitors to control cell growth and metastasis [15-18]. Plant-derived products possess anti-oxidant, anti-cancerous, anti-inflammatory, anti-diabetic, anti-microbial, and hepato-protective features [19].

This study reports the binding efficiency and mechanism of interaction of ellagic acid (EA) to the CDK6 using a combined in silico and in vitro assays. Molecular docking was performed to dissect the mode of interaction of EA with CDK6. Molecular dynamics (MD) simulations investigated the stability of the CDK6-EA system. Enzyme assay suggested significant inhibition of CDK6 by EA. Further, fluorescence binding studies, complemented by the isothermal titration calorimetry (ITC), suggested that EA binds to CDK6 with excellent affinity and a stable CDK6-EA complex is formed. Cell-based expression and therapeutic evaluation showed that EA treatment decreases the expression of CDK6, inhibited cell proliferation, and induces apoptosis in the breast cancer cells.

\section{Results and Discussion}

\subsection{Cloning, Expression, and Purification of CDK6}

The CDK6 gene from plasmid pcDNA was amplified by PCR, with NcoI and XhoI site at the $5^{\prime}$ and $3^{\prime}$ ends, respectively. The size of the amplified product was 981bp (Figure S1A). It was digested with $\mathrm{NcoI}$ and $\mathrm{XhoI}$ and subsequently ligated into $\mathrm{pET} 28 \mathrm{a}^{+}$backbone digested with similar restriction enzymes. The ligated product was transformed into E. coli and positive colonies were selected and confirmed by colony PCR (Figure S1B). The positive clones were confirmed with the help of restriction digestion using $\mathrm{NcoI}$ and $\mathrm{XhoI}$ endonucleases (Figure S1C). Finally, the constructed plasmid was verified by DNA sequencing. The confirmed plasmid construct $\mathrm{pET}^{28 \mathrm{a}^{+}}$with $\mathrm{CDK} 6$ was transformed into $E$. 
coli BL21 $\left(\right.$ codon $\left.^{+}\right)$. The recombinant protein was expressed at $18^{\circ} \mathrm{C}$ by inducing it with $0.5 \mathrm{mM}$ IPTG for $20 \mathrm{~h}$. The over-expression of CDK6 was observed using SDS-PAGE with an apparent molecular weight of $37 \mathrm{kDa}$ (Figure S2A). The CDK6 was purified using Ni-NTA chromatography (Figure S2B). A single band was observed on the SDS-PAGE confirms the purity of CDK6. The purified CDK6 was finally confirmed using Western blot (Figure S2C). The purified protein was subjected to absorption spectrum measurements in the range of 240-340 nm, which revealed proper folding of purified CDK6 without any aggregation (Figure S3).

\subsection{Docking-Based Screening of Natural Compounds}

Molecular docking was used to screen a series of natural compounds, limonene, ursolic aid, caffeic acid, ferulic acid, tocopherol, capsaicin, and EA to select the best inhibitors of CDK6. Binding affinities and interactions of ligand to functionally important residues of CDK6 were calculated by docking and subsequently in vitro fluorescence binding studies were performed to select the best possible inhibitor of CDK6 (Table SI). Information about the active site of CDK6 was obtained from the published report [20]. The ATP-binding site of CDK6 is predominated by the Lys43, Phe98, His100, Asp104, Thr107, and Asp163. EA binds to the same pocket with three hydrogen bonds offered by Glu99 and Asp163 (Figure 1). The oxygen of the carbonyl group of Glu99 forms the hydrogen bond with the $\mathrm{H} 28$ of the EA with the electropositive characteristic provided by the $\mathrm{O} 6$ atom present in the vicinity. In contrast to Glu99, the hydrogen bonding of Asp163 was observed with the side chain in which interaction was observed with the $\mathrm{O} 1$ and $\mathrm{O} 3$ of the EA. The 22nd pose was selected based on the scoring of the docked poses with a free energy of binding of $-6.25 \mathrm{kcal} / \mathrm{mol}$ and inhibition constant of $26.35 \mu \mathrm{M}$. These results suggested that EA binds strongly to the active site pocket of CDK6 and subsequently inhibits its activity. The selected docked system was subjected to MD simulations for further analysis.

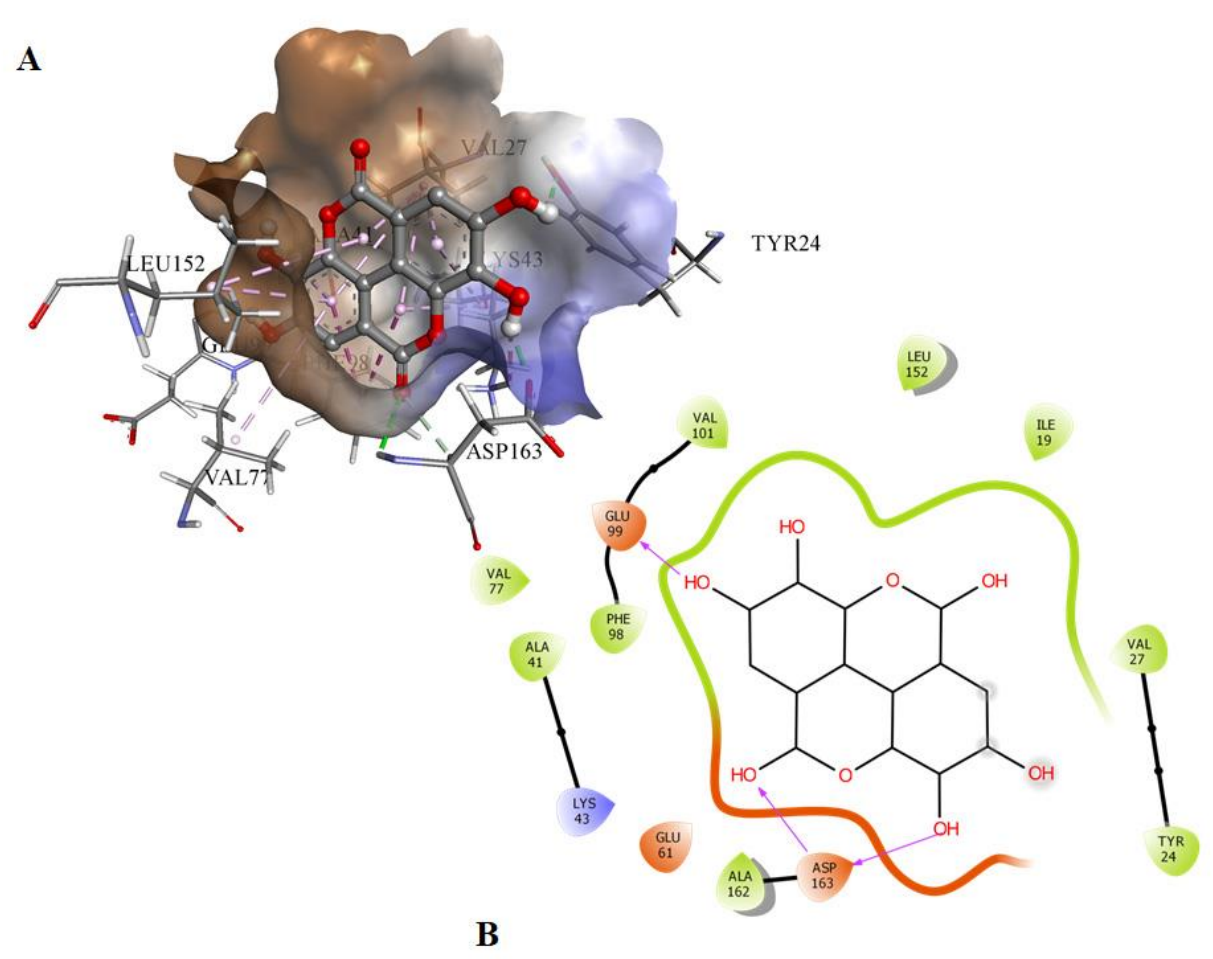

Figure 1. (A) The docked conformation of EA and CDK6 in the 3-D view showing the bound orientation of the inhibitor. (B) The 2-D view of the docked complexes highlighting the observed hydrogen bonds between the inhibitor and protein molecules. 


\subsection{Simulations}

To identify the impact of EA binding on the conformation of CDK6, we have performed MD simulation for both EA-bound and unbound forms of CDK6 on a time scale of $200 \mathrm{~ns}$ (Total $400 \mathrm{~ns}$ ). EA binding induces a closed conformation of CDK6, which is indicative of the computed distance of $0.15-0.3 \mathrm{~nm}$ as well as from the number of existed hydrogen bonds up to nine between the CDK6 and EA during MD simulations (Figure 2A). The stability of the system was further assessed using the calculated radius of gyration $\left(R_{\mathrm{g}}\right)$ and root mean square deviation (RMSD) values, which showed that the system achieved an equilibrium after $120 \mathrm{~ns}$ (Figure 2B). There is a visible difference in the $R_{\mathrm{g}}$ and RMSD values between the EA and bound and unbound forms of CDK6. We noticed that the bound form is slightly less stable than the unbound form of CDK6, indicating a perturbation in the structure after EA binding.

A
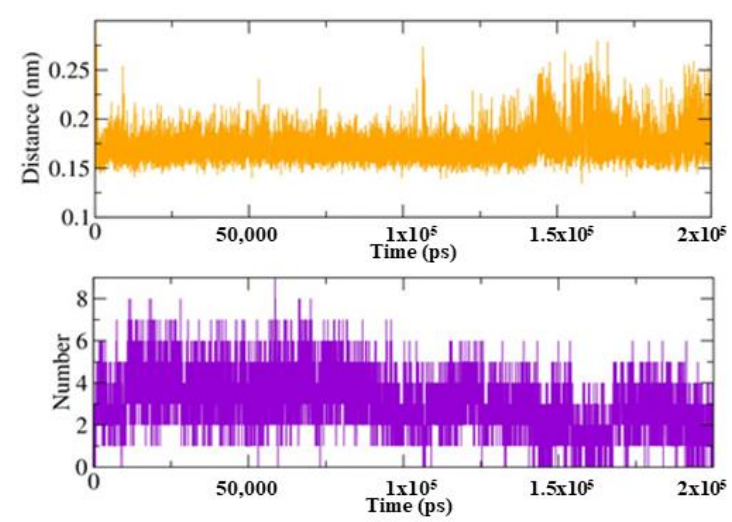

B
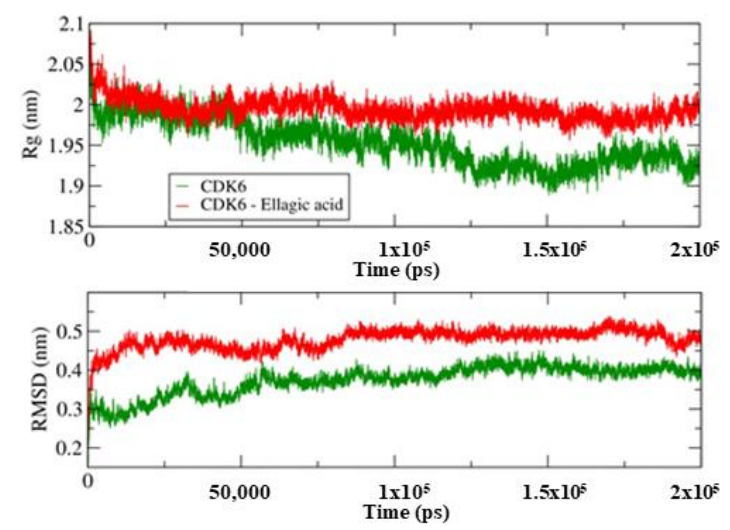

C

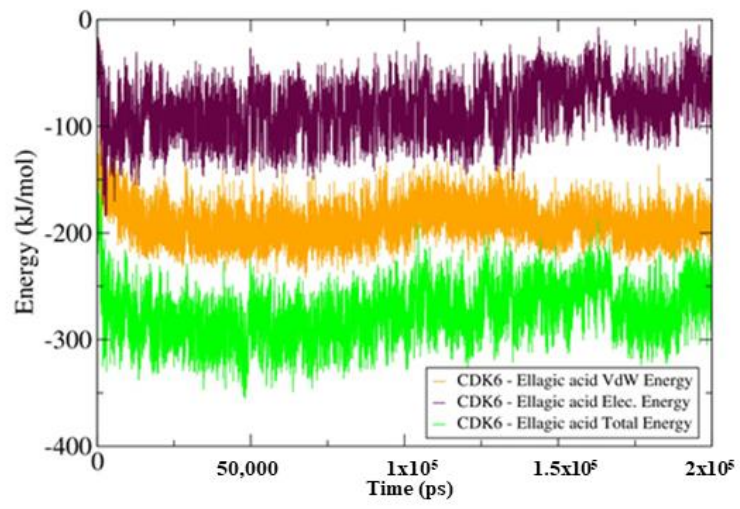

Figure 2. (A) Upper panel shows a plot of changes in the distance between the CDK6 and EA. The lower panel shows the number of hydrogen bond fluctuation curve highlighting the changes in the observed number. (B) The upper panel shows the $R_{\mathrm{g}}$ curves, an indication of compactness. The lower panel corresponds to the RMSD plots to highlight the conformational changes in the CDK6 upon EA binding. (C) The MMPBSA-based generated curves showing changes in the total, electrostatic, and van der Waals energies between the CDK6 and CDK6-EA complex.

The active site of the CDK6 is occupied by Lys43, Phe98, His100, Asp104, Thr107, and Asp163. A significant difference in the fluctuations of constituent residues of EA-bound and unbound conformations of CDK6 was observed (Figure 3A). The active site residues form $\beta 3, \beta 5, L 8, \beta 6$, $\alpha 3$, and L12 regions of the secondary structure elements showed relatively lower motion in the constituent residues in the unbound form of the CDK6, which indicated the presence of lower relative energy as compared to the bound form. Furthermore, the flexibility of the conformational states of both EA-bound and unbound forms were assessed using Principle Component Analysis (PCA), a statistical technique used for the reduction of the data complexity and is significant in assessing the variation 
in the atomic motion in biomolecules in the course of MD simulation. A set of eigenvectors and eigenvalues were used to describe the motion of the protein atomic structure. The PCA is significant in the established correlation between the protein functionalities and conformation. The EA-bound form occupies a larger conformational space as compared to the unbound conformation of the CDK6 (Figure 3B), indicating the occurrence of higher structural stability in the unbound form as compared to the bound form.

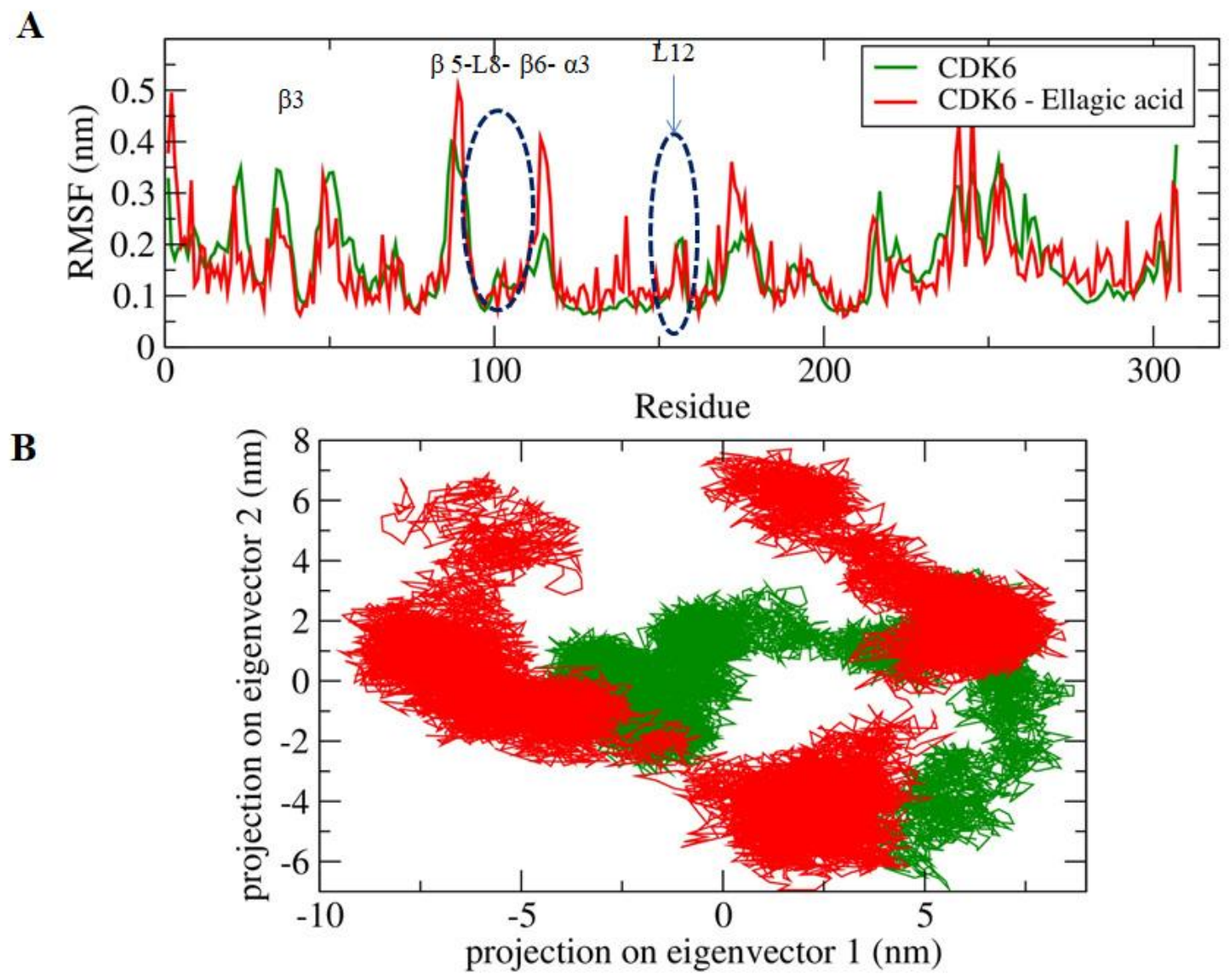

Figure 3. (A) The graphical representation of the changes observed in the fluctuation of the constituent residues between the EA bound and unbound CDK6. (B) The 2-D eigenvector projection plot showing the differences between the flexibility of the two studied forms.

The difference in the folding pattern between the bound and the unbound form of CDK6 was further studied by analyzing the free energy landscapes of the two conformations. A distinct difference in the free energies was observed between the two conformations (Figure 4). In the free CDK6, favored energy and relatively stable conformation were observed (Figure $4 \mathrm{~A}, \mathrm{~B}$ ) as compared to the EA-bound form, indicating that EA-binding to CDK6 perturbs its folding pattern and inhibits the functionality of the protein. Further, the MMPBSA-based algorithms were used for the calculation of the energies present between the CDK6 and EA in the docked complexes (Figure 4C,D). The total free energy of binding between the protein and the inhibitor was observed between -300 to $-350 \mathrm{~kJ} / \mathrm{mol}$ with electrostatic energy as the major contributor to the binding of the EA with CDK6. This observation validated the reliability of the EA-binding to the CDK6. 
A

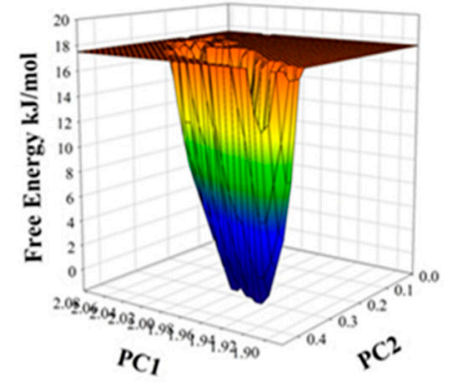

C
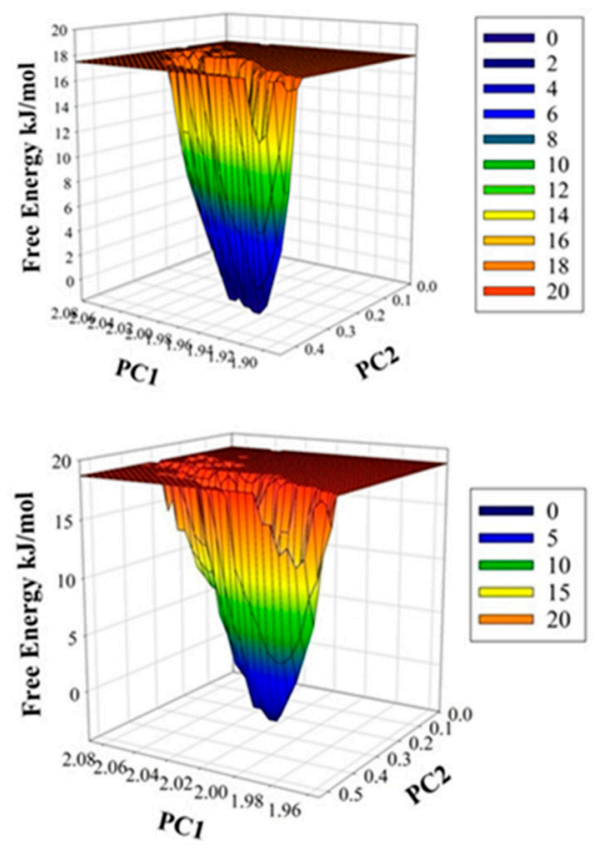

B

D
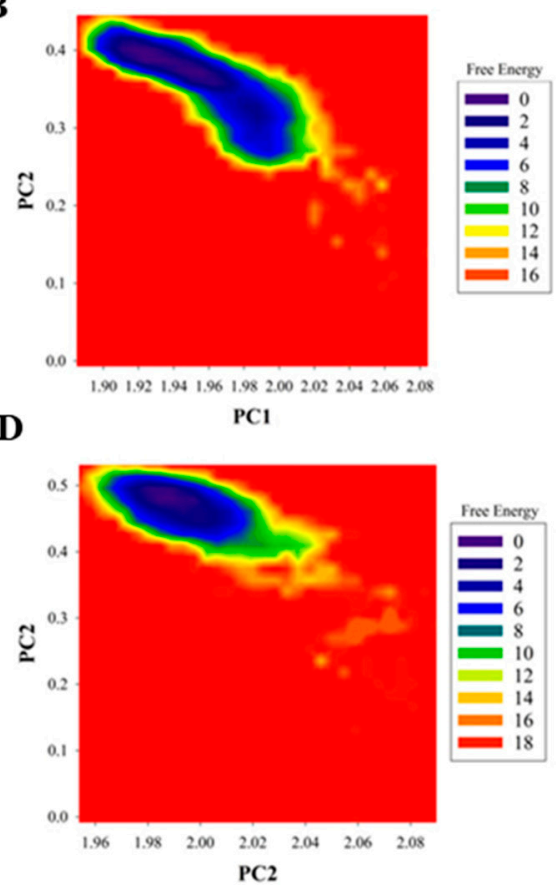

Figure 4. Plots of (A) free energy landscape and (B) Contour map for the of CDK6. A graphical representation of the $(\mathbf{C})$ free energy landscape and (D) Contour map for the of CDK6-EA.

\subsection{Binding Affinity and Thermodynamics of CDK6-EA Interaction}

To further complement our in-silico studies, fluorescence spectra measurements were carried out. Intrinsic fluorescence of a protein is an indicator of changes in the microenvironment of buried tryptophan upon ligand binding. Upon ligand binding, fluorescence quenching occurs, which is defined as a reduction in the fluorescence intensity with a subsequent rise in the ligand concentration [21]. This quenching can either be static or dynamic or a combination of both. As we increase the EA concentration, a significant decrease in the fluorescence intensity of CDK6 was observed, indicating an excellent binding affinity, $K=2.6 \times 10^{7} \mathrm{M}^{-1}$ (Figure 5).

A

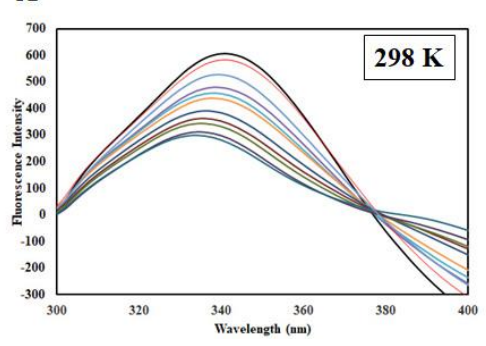

B

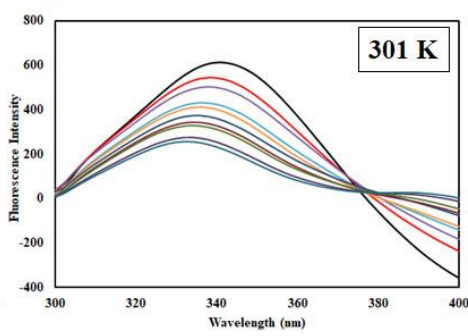

C

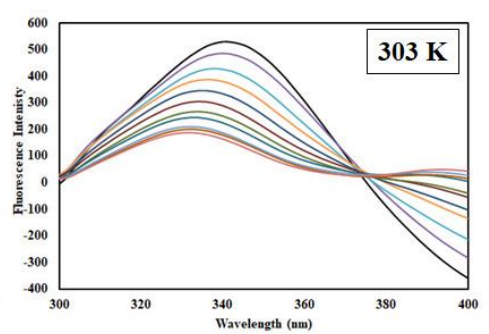

Figure 5. Steady-state fluorescence of CDK6 in the absence and presence of EA (1-10 $\mu \mathrm{M})$ at (A) $298 \mathrm{~K}$, (B) $301 \mathrm{~K}$, and (C) $303 \mathrm{~K}$.

EA binding to the CDK6 causes an alteration in the Trp microenvironment that causes a decline in the fluorescence intensity, which was mathematically fitted to estimate binding parameters. A change in such parameters as a function of temperature can be used to differentiate between static and dynamic modes of quenching [22]. Fluorescence intensity was measured at three different temperatures (298, 301, and $303 \mathrm{~K})$. A decrease in the fluorescence intensity with increasing EA concentration was fitted into the modified Stern-Volmer equation, a plot of $F_{0} / F \mathrm{v} / \mathrm{s}[C]$; the slope of the plot giving Stern-Volmer constant $K_{\mathrm{sv}}$ at fixed intercept after linear regression (Figure 6A). For the calculation of $K_{\mathrm{sv}}$, only linear points were taken into consideration. If there is a linear dependence between $F_{0} / F$ v/s $[C]$, 
it is suggesting the existence of only one mode of quenching, either static or dynamic because the characteristic Stern-Volmer plot of combined quenching (both static and dynamic) is an upward curvature. Table 1 listed the values of obtained $K_{\mathrm{sv}}$ at three different temperatures. We found that $K_{\mathrm{sv}}$ increases with a corresponding increase in temperature. The $K_{\mathrm{sv}}$ value decreases with increasing temperature for static quenching as a result of complex formation, which undergoes dissociation by increasing the temperature while the reverse effect is observed for dynamic quenching, where $K_{\mathrm{sv}}$ increases with temperature because of higher temperature resulting in faster diffusion of the quencher and hence larger extent of collisional quenching [22]. Thus, we concluded that dynamic quenching governs the CDK6-EA complex formation.
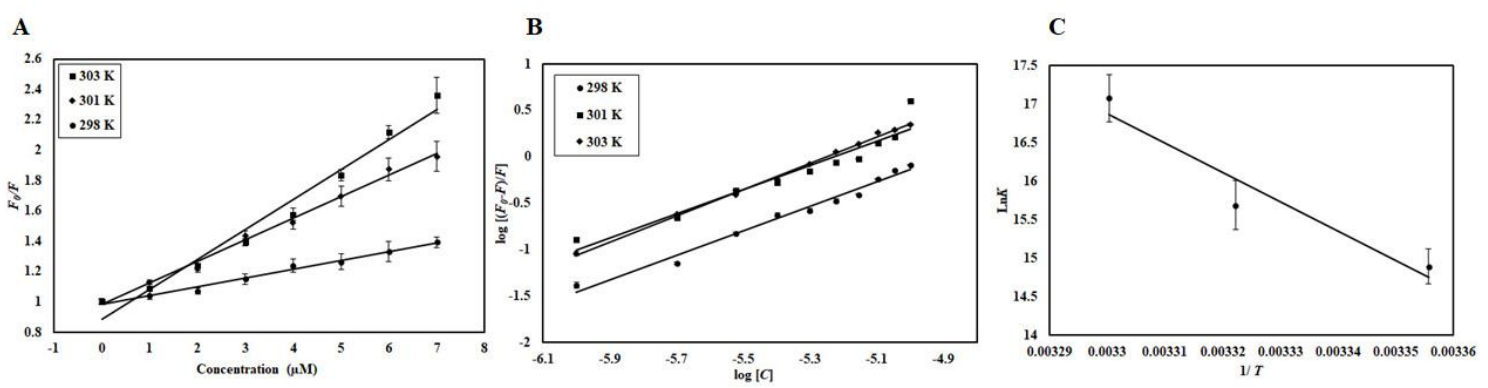

Figure 6. (A) Stern-Volmer plots, (B) Modified Stern-Volmer plots, and (C) van't Hoff plots of CDK6-EA interaction at three temperatures $(298 \mathrm{~K}, 301 \mathrm{~K}$, and $303 \mathrm{~K})$.

Table 1. Thermodynamic parameters of CDK6-EA obtained through a Stern-Volmer plot.

\begin{tabular}{cccc}
\hline Temperature (K) & $\boldsymbol{K}_{\text {sv }} \mathbf{( \mathbf { 1 0 } ^ { \mathbf { 4 } } \mathbf { M } ^ { - \mathbf { 1 } } )}$ & $\boldsymbol{K}_{\boldsymbol{q}}\left(\mathbf{\mathbf { 1 0 } ^ { \mathbf { 1 2 } }} \mathbf{M}^{\mathbf{- 1}} \mathbf{s}^{\mathbf{1}}\right)$ & $\mathbf{R}^{\mathbf{2}}$ \\
\hline 298 & 5.8 & 5.8 & 0.97 \\
\hline 301 & 14.2 & 14.2 & 0.99 \\
\hline 303 & 19.8 & 19.8 & 0.98 \\
\hline
\end{tabular}

The mode of quenching was further validated from the value of the bimolecular quenching rate constant, $K_{q}$, listed in Table 1 . The value of $K_{q}$ for CDK6-EA interaction was higher than the maximum scatter collision quenching constant of different quenchers with biopolymers $\left(2 \times 10^{10} \mathrm{M}^{-1} \mathrm{~s}^{-1}\right)$ suggesting a static mode of quenching to be operative in the case of CDK6-EA binding. Based on these observations, we concluded that CDK6-EA quenching is guided by a mixture of both static and dynamic modes of quenching.

The modified Stern-Volmer equation was employed to estimate binding constant $(K)$ and the number of binding sites $(n)$. Figure $6 \mathrm{~B}$ shows experimental data fitting as per the modified Stern-Volmer equation; the intercept of this plot gives the value of $K$ while the slope gives the number of binding sites, $n$. Table 2 shows the $K$ obtained at different temperatures and it was found that a more stable complex is formed at higher temperatures evident from the increase in $K$ with a corresponding temperature rise. The value of binding constant $(K)$ was found to be $2.6 \times 10^{7} \mathrm{M}^{-1}$ at $303 \mathrm{~K}$, indicating a very strong interaction between CDK6 and EA as this range is reported for other complexes [23,24]. Fluorescence-based studies further validated our previous observations and suggested a strong interaction between CDK6 and EA. 
Table 2. Thermodynamic parameters of CDK6-EA interaction.

\begin{tabular}{|c|c|c|c|c|c|c|}
\hline $\begin{array}{l}\text { Temperature } \\
\text { (K) }\end{array}$ & $\begin{array}{c}K \\
\left(10^{7} M^{-1}\right)\end{array}$ & $n$ & $\begin{array}{c}\Delta G^{\circ} \\
\left(\mathrm{kcal} \mathrm{mol}^{-1}\right)\end{array}$ & 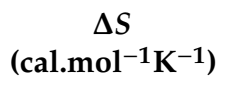 & $\begin{array}{c}\Delta H^{\circ} \\
\left(\mathrm{kcal} \mathrm{mol}^{-1}\right)\end{array}$ & $\begin{array}{c}T \Delta S^{\circ} \\
\left(\mathrm{kcal} \mathrm{mol}^{-1}\right)\end{array}$ \\
\hline 298 & 0.29 & 1.32 & -8.73 & \multirow{3}{*}{283.9087} & \multirow{3}{*}{75.8657} & 84.60 \\
\hline 301 & 0.65 & 1.16 & -9.59 & & & 85.45 \\
\hline 303 & 2.6 & 1.41 & -10.16 & & & 86.02 \\
\hline
\end{tabular}

Electrostatic, hydrogen bonds, van der Waals, and hydrophobic interactions are major forces involved in protein-ligand interactions. The magnitudes and signs of thermodynamic parameters $\left(\Delta H^{\circ}, \Delta S^{\circ}\right.$, and $\left.\Delta G^{\circ}\right)$ are used to understand which forces govern the reaction. Equation (1) was used to find all thermodynamic parameters associated with CDK6-EA interaction. Figure 6C shows the van 't Hoff plot shows the dependence of binding constant $(K)$ on $1 / T$, the slope of which is equal to $-\Delta \mathrm{H} / \mathrm{R}$, and the intercept gives an estimate of $\Delta S / \mathrm{R}$. Table 2 depicts all the thermodynamic parameters obtained for CDK6-EA interaction. When the values of $\Delta H^{\circ}$ and $\Delta S^{\circ}$ are negative, the dominant forces are van der Waals force and hydrogen bonding, while the positive values of $\Delta H^{\circ}$ and $\Delta S^{\circ}$ mark the existence of hydrophobic interactions [25]. For CDK6-EA interaction, positive values of $\Delta H^{\circ}$ and $\Delta S^{\circ}$ suggested that interaction was driven by dominant hydrophobic interactions.

\subsection{Isothermal Titration Calorimetry}

An ITC experiment was performed to estimate thermodynamic parameters like change in entropy $(\Delta S)$, number of binding sites $(n)$, Gibbs free energy $(\Delta G)$, change in enthalpy $(\Delta H)$, and binding constant $\left(K_{a}\right)$ to further complement fluorescence binding studies [26]. A representative calorimetric isotherm is shown in Figure 7A, in which every peak corresponds to a single round of injection of EA into the CDK6. Figure 7B shows the enthalpy change with each injection as a function of the molar ratio of EA into CDK6. This data was obtained for the model of one binding site. The thermodynamic parameters obtained for CDK6-EA interaction were: $K_{\mathrm{a}}=2.52 \times 10^{4} \pm 8.8 \times 10^{3} \mathrm{M}^{-1}, \Delta H=-1.18 \times$ $10^{8} \pm 2.25 \times 10^{10} \mathrm{kcal} \mathrm{mol}^{-1}$, and $\Delta S=-3.99 \times 10^{5} \mathrm{cal}^{\mathrm{mol}} \mathrm{mo}^{-1} \mathrm{~K}^{-1}$. Interestingly, there is a noticeable difference in the thermodynamic parameters estimated using ITC and fluorescence, but such variations were observed earlier in other studies due to the assumptions made in noncalorimetric approaches that $\Delta H$ does not depend on temperature $[27,28]$. Furthermore, ITC interprets an overall change in a particular parameter while fluorescence spectroscopy measures a local change in the Trp.

\subsection{Enzyme Inhibition Assay}

To investigate the consequence of EA on the kinase activity of CDK6, enzyme activity assay was carried out with increasing concentrations of EA $(1-10 \mu \mathrm{M})$ (Figure 7C). Enzyme activity was performed as per our previously published protocols $[29,30]$. It is quite apparent from the inhibition data that the activity of CDK6 decreases with increasing concentration of EA and shows a concentration-dependent relationship. $\mathrm{IC}_{50}$ was calculated with an AAT Bioquest calculator [31] (Figure S3C) and was found to be $3.053 \mu \mathrm{M}$. These observations suggested that EA is a strong inhibitor of CDK6.

\subsection{Cell Viability Studies}

CDK6 is an important drug target for varying types of cancers, but most prominently used for the targeting of breast cancer [32,33]. We have evaluated the effect of EA treatment on the cell viabilities of MCF-7 and MDA-MB-231 human breast cancer cell lines. Cell viability studies showed a significant decrease in the proliferation of selected cancer cells (Figure 8A). Interestingly, results showed that EA treatment inhibited the growth of cancer cells in a dose-dependent manner, with $\mathrm{IC}_{50}$ values of $29.12 \pm 1.15 \mu \mathrm{M}$ and $20.51 \pm 1.22 \mu \mathrm{M}$, respectively (Figure 8A). Cell viability assay indicated that EA significantly decreases the viability or proliferation of studied human breast cancer cell lines. 


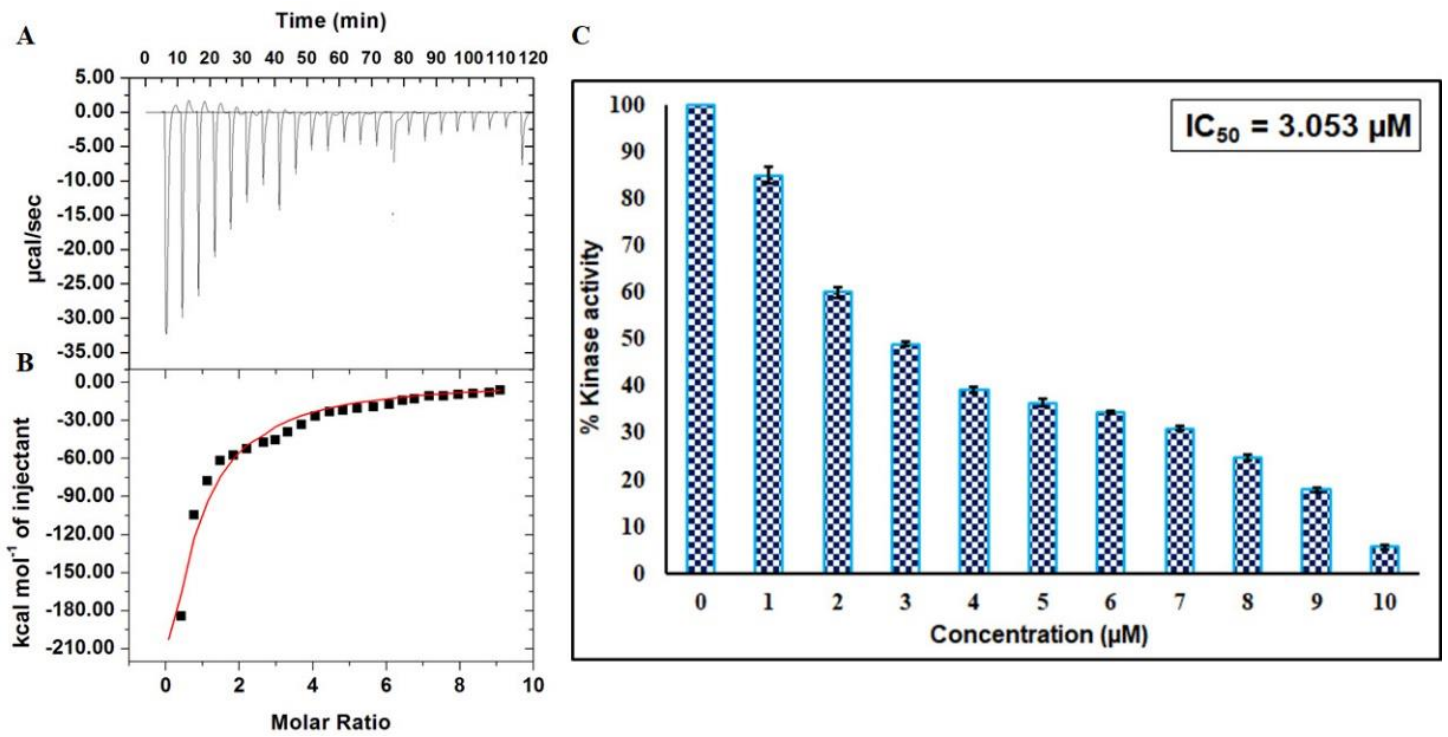

Figure 7. Binding and enzyme inhibition studies of EA with CDK6: (A) Representative thermogram showing the heat of dilutions of EA with CDK6. (B) Binding isotherm for the titration of EA with CDK6 at $25{ }^{\circ} \mathrm{C}$. The molar concentration of CDK6 in the sample cell was $15 \mu \mathrm{M}$. EA molar concentration in the syringe was $500 \mu \mathrm{M}$. (C) ATPase inhibition assay of CDK6 with increasing concentration of EA $(0-10 \mu \mathrm{M})$. The activity of native CDK6 was taken as $100 \%$ for reference.

\subsection{CDK6 Expression Studies}

Enzyme inhibition and binding studies of EA with CDK6 suggested a high binding affinity and inhibition in the kinase activity. EA decreases the cell viability of breast cancer cells, so to confirm whether EA decreases the cellular expression of CDK6 or not, we have performed an expression study of CDK6 in EA-treated/control cells. Interestingly, we found that EA decreases the expression of CDK6 in MCF-7 and MDA-MB-231 cancer cells (Figure 8B). Figure S4 depicts uncropped images of membrane probed with $\mathrm{CDK} 6$ and actin antibodies after EA treatments. These results suggest that EA downregulates the expression of CDK6 at the translational level also and thus supported the results of enzyme inhibition and binding studies.

\subsection{Colony Formation and Apoptosis Studies}

CDK6 supported the colonization and apoptotic evasion of cancer cells [34]. Thus, CDK6 inhibition is an innovative strategy to decrease the colonization and apoptotic induction in cancer cells. We further analyzed the effect of EA on colony formation and apoptosis of MCF-7 and MDA-MB-231 cells. Results of colony formation studies showed that EA treatment decreases the number of colonies significantly, as compared to vehicle control (Figure $8 \mathrm{C}, \mathrm{D}$ ). Subsequently, we evaluated the apoptotic potential of EA in MCF-7 and MDA-MB-231 cells. The cells were treated with the respective $\mathrm{IC}_{50}$ concentration of EA for $48 \mathrm{~h}$ and processed for annexin- $\mathrm{V}$ staining and found that EA induces apoptosis in $23.3 \%$ and $27.9 \%$ of MCF-7 and MDA-MB-231 cells, respectively (Figure 8E). These observations of colony formation and apoptosis studies suggested that EA has a great potential to reduce the colonization of selected breast cancer cells and induces apoptosis. 
A.

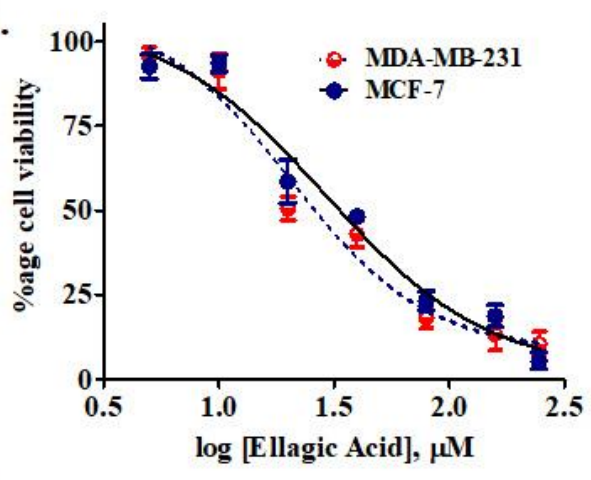

C.

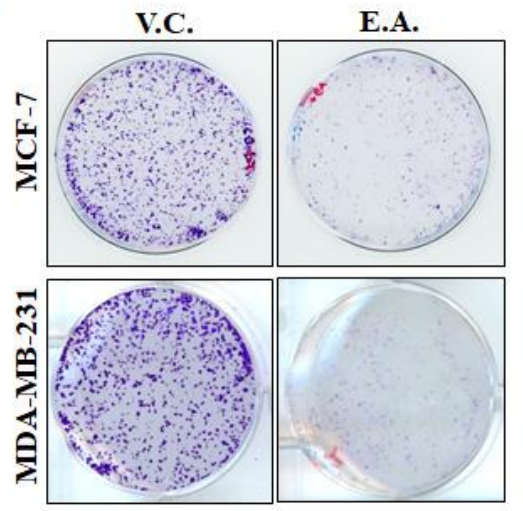

B.

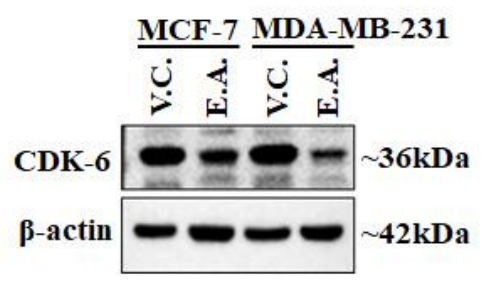

D.

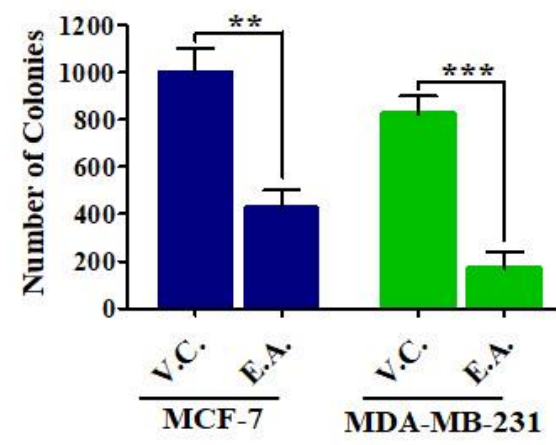

E.

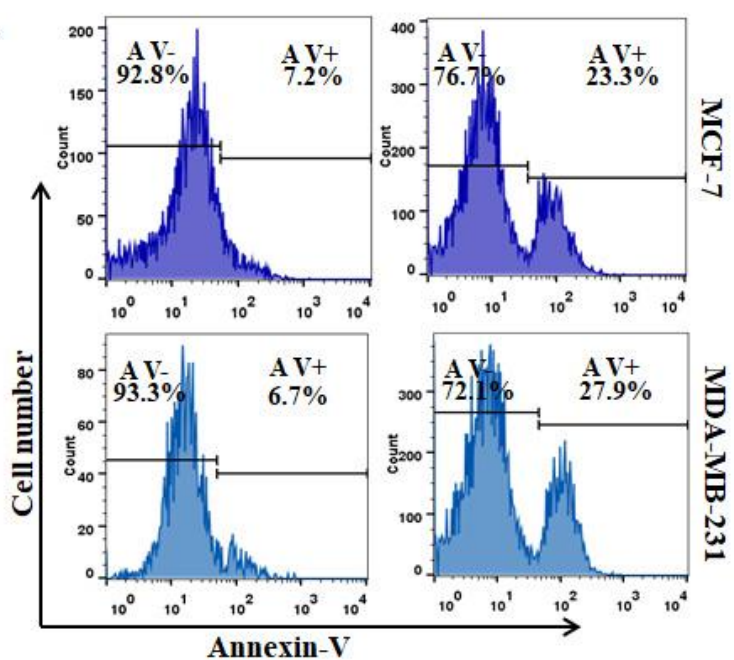

Figure 8. Treatment of EA decreases cell viability, CDK6 expression, colonization, and induces apoptosis in cancer cells. (A) The cell proliferation profile showing the effect of EA treatment on the viabilities of MCF-7 and MDA-MB-231 cells. The selected cancer cells were incubated with an increasing dose of EA for $48 \mathrm{~h}$ and respective cell viabilities were estimated using MTT assay. Each data point shown is the mean \pm SD from $n=3$. (B) Protein expression of CDK6 in EA and vehicle-treated MCF-7 and MDA-MB-231 cells. (C) Colony formation assay performed with respective IC $_{50}$ concentrations of EA with selected cell lines. (D) The bar graph representation for the total number of colonies in each treatment group and compared with the vehicle controls. (E) Apoptosis studies showing the percentage of Annexin-V positive/negative cells stained after EA treatment for $48 \mathrm{~h}$. The data were statistically analyzed using Student's $t$-test for unpaired samples, ${ }^{* *} p<0.01{ }^{* * *} p<0.001$ compared to the vehicle control group. 


\section{Discussion}

Most of the human cancers involve a deviation from normal signaling cascades [35,36]. Protein kinases govern the important steps of these signaling pathways and any unusual activation of the signaling cascades can be controlled by targeting these kinases [15,37]. Thus, at present, this domain has attracted the interest of researchers across the globe and anticancer therapeutics is largely devoted to the identification of molecules targeting these kinases [38-40]. In search of the development of therapeutic molecules against these kinases, natural products are at the heart of this due to their wide therapeutic potential along with minimum side effects. Natural products demonstrate the wealthy origin of novel molecular scaffolds for synthetic chemists who deploy these for the development of drugs and drug leads [41]. Thus, owing to all these properties, these compounds have been used as leads for drug discovery. Since ancient times, many phytochemicals or plant-based products have been effective to treat a wide variety of human disorders. This is attributed to the fact that these natural compounds possess broad-spectrum properties namely antioxidant [42], anti-inflammatory [43], anti-cancer activities, and many more. Thus, considering all these important properties of plant-based products, this study investigates the potential inhibitors of CDK6.

This study screens a series of plant-derived natural compounds against CDK6 to find a potent inhibitor of CDK6 that can be used as a drug lead in CDK6 directed cancers. Initially, CDK6 was cloned, expressed, and purified. After screening through molecular docking and fluorescence-based binding study, EA was selected for detailed analysis. EA is a dietary polyphenol widely found in fruits and vegetables and has well-established anti-cancerous properties [44]. EA is a pharmacologically significant polyphenol that is a promising compound in anticancer therapy [45]. Molecular docking of EA with CDK6 provided an insight into the binding pattern highlighting that EA binds to the ATP binding pocket of CDK6-forming covalent interactions with functionally important residues of CDK6. Additionally, molecular dynamics simulation of $200 \mathrm{~ns}$ was performed to have an atomistic detail of binding of EA to CDK6. Binding of EA to CDK6 induces a closed conformation of CDK6, which is implicated from the computed distance of $0.15-0.3 \mathrm{~nm}$ coupled with prevailing hydrogen bonds between the CDK6 and EA during MD simulations. Further, the stability of the system was also implicated from calculated $R_{\mathrm{g}}$ and RMSD values, which suggested the achievement of equilibration after $120 \mathrm{~ns}$. The variation in $R_{\mathrm{g}}$ and RMSD values suggested that EA-bound CDK6 is slightly less stable as compared to free CDK6. Besides, the flexibility of the conformational states of free CDK6 and EA-bound CDK6 was analyzed using PCA which also showed that EA-bound CDK6 occupies a larger conformational space as compared to free CDK6. Further, free energy landscapes of both the conformations also implied that binding of EA to CDK6 perturbs its folding pattern, thereby inhibiting the functionality of the protein.

Fluorescence quenching studies suggested that EA binds to CDK6 with excellent affinity. Moreover, fluorescence spectroscopy carried out as a function of temperature provided an insight into the operative quenching mode of CDK6-EA interaction. The variation in binding parameters with temperature suggested that CDK6-EA quenching is guided by a mixture of static and dynamic modes of quenching. Thermodynamic analysis of CDK6-EA interaction showed $\Delta H^{\circ}$ and $\Delta S^{\circ}$ values in the positive range, thereby suggesting that prevalent forces driving this reaction were hydrophobic interactions. ITC further validated strong binding between $\mathrm{CDK} 6$ and EA with obtained binding parameters of significant values. ATPase activity of EA suggested it to be a potent inhibitor of CDK6 with an admirable $\mathrm{IC}_{50}$ value of $3.053 \mu \mathrm{M}$.

The success of therapeutic molecules in anticancer therapy also ascertains from their capability to selectively kill cancer cells without showing any cytotoxicity. Thus, a cell viability assay was carried out to see the effect of EA on breast cancer cells. Cell viability assay suggested that EA meaningfully decreases the growth of human breast cancer cells in the submicromolar range. These studies are also in close agreement with previous reports, which suggested that EA treatment decreases the growth of different human cancer cells [29,44]. Further, expression study of CDK6 in EA-treated/control cells indicated that EA decreases the expression of CDK6 in MCF-7 and MDA-MB-231 cells implying that 
along with the activity inhibition, EA also decreases the expression of CDK6 at the translational level. These observations validate our enzyme assay results and binding study observations. Further, colony formation and apoptosis suggested that EA is a potent compound that can reduce the colonization of selected breast cancer cells and induces apoptosis. Apoptosis studies are also in close agreement with some previous studies, which suggested that EA induces apoptosis in A549 cells via phosphoinositide 3-kinase/protein kinase B pathway. In addition to these reports, our observations suggested that EA could also induce apoptosis in a CDK6-dependent manner. Overall, the present study provides a different and novel insight into the possible targets of EA, particularly in cancer cells where the expression of CDK6 is high. The outcomes of this study also warrant a further detailed therapeutic evaluation of EA concerning the CDK6 targetted therapies.

\section{Materials and Methods}

\subsection{Chemicals and Reagents}

The gene for CDK6 was obtained from Harvard Medical School and subsequently sub-cloned in the prokaryotic expression vector; pET-28 $\mathrm{a}^{+}$plasmid (Novagen, WI, USA). For cloning purposes, the DH5 $\alpha$ strain of E. coli was used while BL21 (codon ${ }^{+}$) strain was used as the expression of recombinant CDK6 protein. Using the previous protocol, plasmid isolation, restriction enzyme digestion, ligation, and competent cell preparation was performed [18]. DifcoTM LB broth Miller (Fisher Scientific, Lenexa, KS, USA) for bacterial culture was from Becton, Dickinson, and Company, MD, USA. Annexin-V/PI staining kit was procured from BD-Biosciences (San Jose, CA, USA). Reagents for cell proliferation study were procured from Thermo Fisher Scientific (Waltham, MA USA). Breast cancer lines, MCF-7, and MDA-MB-231 were borrowed from National Centre for Cell Sciences (Pune, India).

\subsection{Cloning, Expression, and Purification of CDK6}

The 981-bp coding region (326 amino acids) was amplified by PCR from plasmid pcDNA containing the CDK6 gene including the restriction sites $\mathrm{NcoI}$ and $\mathrm{XhoI}$ on each end. The CDK6 gene was ligated into $\mathrm{pET} 28 \mathrm{a}^{+}$vector digested with a similar restriction enzyme to generate complementary sticky ends. The ligated product was verified using restriction digestion method. Finally, the orientation and gene sequence ligated into the expression vector was verified using gene sequencing.

Using a standard protocol, the constructed expression vector $(\mathrm{pET} 28 \mathrm{a}+)$ comprising the coding region of the CDK6 was transformed into E. coli BL21 (codon ${ }^{+}$) and selected using kanamycin. The overnight bacterial culture of the expression cells was transformed and CDK6 expression was induced by the IPTG. Once culture was full-grown, subjected to centrifugation, lysis, and obtained supernatant and pellet were checked on sodium dodecyl sulfate-polyacrylamide gel electrophoresis (SDS-PAGE) to confirm the presence of protein in the soluble or insoluble fraction.

The major portion of CDK6 was found in the inclusion bodies (IBs). To purify CDK6 from IBs we followed standard procedure and solubilized IBs were centrifuged and the supernatant was loaded on preequilibrated Ni-NTA Column (50 mM Tris buffer $\mathrm{pH} 8.0,200 \mathrm{mM} \mathrm{NaCl}$ and $0.3 \%$ $\mathrm{N}$-lauroylsarcosine and $20 \mathrm{mM}$ imidazole). After the binding step, the column was washed, and then bound CDK6 was eluted with the help of elution buffer $(50 \mathrm{mM}$ Tris buffer $\mathrm{pH}$ 8.0, $200 \mathrm{mM} \mathrm{NaCl}$, and $0.1 \% \mathrm{~N}$-lauroylsarcosine, $300 \mathrm{mM}$ imidazole). The fractions of CDK6 were collected and checked for purity by SDS-PAGE. The purified CDK6 was refolded by dialysis and refolded protein was used for all biochemical studies after checking its kinase activity. Western blot was done to confirm the CDK6 after transferring bands of protein from SDS-PAGE to the PVDF membrane. Blot was developed using diaminobenzidine or luminol method [46].

\subsection{Molecular Docking}

The atomics coordinates of the CDK6 structure were downloaded from the Protein Data Bank (PDB ID - 3NUP) and subsequently optimized for modeling the gap in the structures using the "PRIME" 
module of Schrödinger [47,48]. The structure of EA was constructed using drawing utilities present in MAESTRO (Maestro, Schrödinger, LLC, New York, NY, 2018) and the geometries of the resultant ligand structure were optimized by JAGUAR [49].

The Autodock 4 was used to perform the docking between the CDK6 and EA [50], generated output in the form of inhibition constant along with the free energy of binding. The Autodock performs rigid docking, which involves the usage of free energy factors for the classification of bound conformation. The energy factors are derived from the combination of the available empirical force field as well as the Lamarckian Genetic Algorithm [50]. In the primary step, the grid dimensions were set to $44 \times 54 \times 50 \AA$ along with the XYZ directions using the AutoGrid with a spacing of $0.375 \AA$. The maximum efficiency values were set for the Lamarckian genetic algorithm, with the population control was set to 250 as well as the "longer" intervals, which were used for the energy evaluations. The docking was performed on the cluster of Center for High-Performance Computing (CHPC), South Africa, and 100 bound conformations which were grouped based on 2.0 A RMSD tolerance were generated for CDK6 and EA system. The DrugScoreX was used for performing the re-scoring of the generated docked conformations [51]. The best scoring docked complex was subjected to the MD simulations.

\subsection{Simulations}

MD simulations on EA-bound and apo form of CDK6 were performed using GROMACS version 2018-2 [52]. Primarily, the GROMOS96 53a6 force-field was used for the generation of topologies of protein structure in the docking-based generated complexes. Moreover, the topologies of the studied ligand compound were generated using the PRODRG server [53]. But the PRODRG server does not contain the functionality of generating the partial charges of the EA, therefore, the CHELPG program and B3LYP 6-31G $(\mathrm{d}, \mathrm{p})$ basis set present in the DFT method of GAUSSIAN was used for the correction of the partial charges [54]. In the subsequent steps, the solvation of the docked complexes was performed using the SPC/E water model [55] and neutralization was performed by including the counter number of NA and CL ions. Furthermore, the steepest descent algorithm present in the GROMACS was used for minimizing the neutralized solvated system with a convergence criterion of $0.005 \mathrm{kcal} / \mathrm{mol}$. To keep the ligand molecules in the solvated box, the position restraints were applied.

The equilibration step includes a separate NVT (constant volume) stage followed by NPT (constant pressure) ensemble, each at a 100 ps time scale. Using the Berendsen weak coupling method and Parrinello-Rahman barostat, the temperature and the pressure of the simulating system were maintained at $300 \mathrm{~K}$ and $1 \mathrm{bar}$, respectively. The LINCS algorithm was used for the generation of the final conformational production stage for a $200 \mathrm{~ns}$ timescale, and trajectories were generated, which were analyzed to understand the behavior of each complex in the explicit water environment. The changes in the protein-ligand distance, H-bonds, RMSD, $R_{\mathrm{g}}$, RMSF, PCA, and free energy landscapes of the complex system were analyzed. Furthermore, the molecular mechanics Poisson-Boltzmann surface area (MM-PBSA) protocols implemented in the g_mmpbsa package [56] were used for the calculation of free energy of binding protein and the ligand molecules.

\subsection{Enzyme Inhibition Assay}

ATPase assay was performed to see the CDK6 inhibitory activity of EA [57]. For a typical kinase reaction, freshly prepared ATP $(50 \mu \mathrm{M})$ was incubated with CDK6 $(1 \mu \mathrm{M})$ in a reaction volume of $100 \mu \mathrm{L}$ and incubated at $25^{\circ} \mathrm{C}$ for $1 \mathrm{~h}$. Similar reactions were set up with the increasing concentration of EA. Malachite green $(200 \mu \mathrm{L})$ was further added to the reaction mixture to stop the reaction followed by incubation of samples at room temperature for 20-25 $\mathrm{min}$ for the development of color. The absorbance of the final reaction product was measured spectrophotometrically at $620 \mathrm{~nm}$. 


\subsection{Fluorescence Measurements}

To study the binding affinity of EA with the recombinant CDK6, a fluorescence binding study was performed. CDK6 was titrated with the EA and corresponding emission spectra were recorded in the range of 300-400 nm after carrying out excitation at $280 \mathrm{~nm}$. The inner filter effect [58] was corrected for the obtained intensities. Fluorescence emission spectra were analyzed by the Stern-Volmer equation to find Stern-Volmer constant $\left(K_{S v}\right)$ and modified Stern-Volmer equation to estimate the binding constant $(K)$ and the number of binding sites $(n)$. Other binding features were estimated by our previously described protocol $[40,59]$.

\subsection{Thermodynamics of the Complex}

With each reaction, changes in enthalpy and entropy are associated, which are evidence of the type of reaction taking place. Equation (1) ("van't Hoff equation") [23] was employed to calculate the thermodynamic parameters associated with this binding,

$$
\Delta G=-R T \operatorname{Ln} K=\Delta H-T \Delta S
$$

" $K$ is the obtained binding constant.

" $\Delta H^{\circ}$ is the associated enthalpy change while $\Delta G^{\circ}$ is the associated free Gibbs energy change".

* $\Delta S^{\circ}$ denotes the associated entropy change with reaction and $\mathrm{R}$ is "universal gas constant" $\left(1.987 \mathrm{cal} \mathrm{mol}^{-1} \cdot \mathrm{K}^{-1}\right)$.

\subsection{Isothermal Titration Calorimetry}

ITC measurements were carried out at $25^{\circ} \mathrm{C}$ using a VP-ITC microcalorimeter (MicroCal, Inc, GE, MicroCal, USA). The sample cell was filled with 15-20 $\mu \mathrm{M}$ CDK6 and $500 \mu \mathrm{M}$ EA solution was filled in the syringe. An automated titration was carried out with (including a first false injection of $2 \mu \mathrm{L}$ ) a successive injection of $10 \mu \mathrm{L}$ EA solution into a CDK6 sample cell at a $260 \mathrm{~s}$ interval with $320 \mathrm{rpm}$ stirring speed. For analysis, the heat of dilution of EA in the sample buffer was subtracted from the titration data. MicroCal Origin 8.0 was used to analyze the stoichiometry of binding $(n)$, enthalpy change $(\Delta H)$, an association constant $\left(K_{\mathrm{a}}\right)$.

\subsection{Cell Viability Assay}

Cell viabilities of cancer cells with or without EA were evaluated using MTT assay [28,60]. Briefly, the selected cells (MCF-7 and MDA-MB-231) were seeded in a 96-well (5000-6000 cells/well) culture plate. Overnight grown cells were incubated with EA $(0-250 \mu \mathrm{M})$ for $72 \mathrm{~h}$ in a $\mathrm{CO}_{2}$ incubator, at $37^{\circ} \mathrm{C}$. After a stipulated time of treatment, $20 \mu \mathrm{L}$ of MTT (from $5 \mathrm{mg} / \mathrm{mL}$ stock solution in PBS, pH 7.4) was added to each treatment well of 96-well plate, and plates with MTT solution were incubated additionally for $4-5 \mathrm{~h}$, in the $\mathrm{CO}_{2}$ incubator. Lastly, the formazan were solubilized by adding $100 \mu \mathrm{L}$ of DMSO to each well. The absorbance (A) of the dissolved purple reaction solution was measured at $570 \mathrm{~nm}$. Absorption readings were converted into percent cell viability and used to estimate $50 \%$ inhibitory concentration $\left(\mathrm{IC}_{50}\right)$ of EA for selected cancer cells.

\subsection{Total Protein Isolation and Immunoblotting}

The cell lysates of EA-treated/untreated MCF-7 and MDA-MB-231 cell lines were prepared using RIPA cell lysis buffer (Thermo Fisher Scientific (USA)) and total protein was isolated. The amount of protein was quantified by a BCA-protein estimation kit. Nearly, 50-60 $\mu \mathrm{g}$ of total protein was subjected for SDS-PAGE, and obtained bands were blotted to polyvinylidene fluoride membrane. The protein of interest was identified using respective primary antibodies and horseradish peroxidase (HRP) conjugated secondary IgG using the luminol method [46]. 


\subsection{Colony Formation Assay}

To perceive the effect of EA treatment on the colonogenic potential of selected cell lines colony formation studies were performed as described previously [28]. Briefly, 1500-2000 (MCF-7/MDA-MB-231 cells) cells/well were seeded (in triplicates) in each well of a 6-well cell culture plate. The cells were grown in complete cell growth medium for $48 \mathrm{~h}$ and incubated with respective $\mathrm{IC}_{50}$ concentrations of EA for $10-12$ days, (at $37^{\circ} \mathrm{C}$, in a $5 \% \mathrm{CO}_{2}$ incubator). On the other hand, the control cells were incubated with vehicle control (DMSO) under similar experimental conditions. After 10-12 days, the colonies of cells were fixed with 100\% methanol and subsequently stained using a $0.4 \%$ crystal violet solution (prepared in 25\% methanol. Finally, the colonies obtained after staining were photographed, quantified, plotted, and analyzed by comparing with vehicle control.

\subsection{Apoptosis Assay}

EA was evaluated for its apoptosis-inducing potential on selected cancer cell lines using Annexin-V staining [61]. In brief, cells were plated in a six-well culture plate, and once they reached $\sim 70 \%-80 \%$ confluency, incubated with $\mathrm{IC}_{50}$ concentration of EA or vehicle control for $24 \mathrm{~h}$ at $37^{\circ} \mathrm{C}$. Following the incubation with EA ( $24 \mathrm{~h}$ ), cells were collected, washed two times with PBS, and incubated with Annexin-V/PI stain and analyzed by Flow Cytometry as per manufacturer's protocol (Annexin-V kit, BD-Biosciences, San Jose, USA).

\subsection{Statistical Analysis}

All the experiments were performed at least three times and their average was taken and expressed in mean \pm standard error of the mean (SEM).

\section{Conclusions}

The aberrant activation of signaling cascade is a frequent event in various types of human cancers. CDK6 is directly associated with the progression of different types of cancer because the overexpression of CDK6 resulted in an uncontrolled cell cycle progression and growth. For the identification of therapeutic molecules, natural compounds serve as the source of enormous structural and chemical diversity along with diverse biological activities with fewer side effects. This study identifies EA as a potent inhibitor of CDK6. However, the anticancer properties of EA were reported earlier, but the present study establishes CDK6 as a novel target. Thus, targeting CDK6 by EA can be a smart therapeutic approach to manage CDK6 directed cancers.

Supplementary Materials: Supplementary materials can be found at http:/www.mdpi.com/1422-0067/21/10/ 3526/s1.

Author Contributions: Conceptualization, M.Y., A.S., and M.I.H.; methodology, M.Y., P.K., M.S., and A.S.; software, M.Y., P.K., M.S., and A.S.; validation, M.Y., G.M.H., and M.I.H.; formal analysis, M.Y., A.S., A.H., G.M.H., and P.K.; investigation, M.Y., A.S., P.K., and M.S.; data curation, M.S., G.M.H., and A.I.; writing-original draft preparation, M.Y., A.H., P.K., and M.I.H.; writing-review and editing, M.F.A., A.I., Q.M.R.H., and M.I.H.; visualization, M.Y., A.S., P.K., A.I., and M.F.A.; supervision, Q.M.R.H., and M.I.H.; project administration, Q.M.R.H., and M.I.H.; funding acquisition, M.I.H., and M.F.A. All authors have read and agreed to the published version of the manuscript.

Funding: This work is funded by the Indian Council of Medical Research (Grant No. BIC/12(01)/2015). APC is funded by King Saud University.

Acknowledgments: M.Y. is thankful to the Indian Council of Medical Research (Government of India) for the award of Senior Research Fellowship. M.F.A. and A.H. acknowledge the generous support from Research Supporting Project (No. RSP-2019-122) by King Saud University, Riyadh, Saudi Arabia. Authors thank the Department of Science and Technology, Government of India for the FIST support (FIST program No. SR/FST/LSI-541/2012).

Conflicts of Interest: The authors declare no conflicts of interest. 


\section{References}

1. MacLachlan, T.K.; Sang, N.; Giordano, A. Cyclins, cyclin-dependent kinases, and cdk inhibitors: Implications in cell cycle control and cancer. Crit. Rev. Eukaryot. Gene Expr. 1995, 5, 127-156. [CrossRef]

2. Pavlova, N.N.; Thompson, C.B. The Emerging Hallmarks of Cancer Metabolism. Cell Metab. 2016, $23,27-47$. [CrossRef]

3. Lee, D.J.; Zeidner, J.F. Cyclin-dependent kinase (CDK) 9 and 4/6 inhibitors in acute myeloid leukemia (AML): A promising therapeutic approach. Expert Opin. Investig. Drugs 2019, 28, 989-1001. [CrossRef]

4. Malumbres, M.; Barbacid, M. Mammalian cyclin-dependent kinases. Trends Biochem. Sci. 2005, 30, 630-641. [CrossRef] [PubMed]

5. Mohammad, T.; Batra, S.; Dahiya, R.; Baig, M.H.; Rather, I.A.; Dong, J.J.; Hassan, I. Identification of High-Affinity Inhibitors of Cyclin-Dependent Kinase 2 Towards Anticancer Therapy. Molecules 2019, 24, 4589. [CrossRef]

6. Kastan, M.B.; Bartek, J. Cell-cycle checkpoints and cancer. Nature 2004, 432, 316-323. [CrossRef] [PubMed]

7. Manning, G.; Whyte, D.B.; Martinez, R.; Hunter, T.; Sudarsanam, S. The protein kinase complement of the human genome. Science 2002, 298, 1912-1934. [CrossRef] [PubMed]

8. Russo, A.A.; Tong, L.; Lee, J.-O.; Jeffrey, P.D.; Pavletich, N.P. Structural basis for inhibition of the cyclin-dependent kinase Cdk6 by the tumour suppressor p16 INK4a. Nature 1998, 395, 237-243. [CrossRef]

9. Wang, H.; Nicolay, B.N.; Chick, J.M.; Gao, X.; Geng, Y.; Ren, H.; Gao, H.; Yang, G.; Williams, J.A.; Suski, J.M.; et al. The metabolic function of cyclin D3-CDK6 kinase in cancer cell survival. Nature 2017, 546, 426-430. [CrossRef]

10. Sherr, C.J. Cancer cell cycles. Science 1996, 274, 1672-1677. [CrossRef]

11. Shapiro, G.I. Cyclin-dependent kinase pathways as targets for cancer treatment. J. Clin. Oncol. 2006, 24, 1770-1783. [CrossRef] [PubMed]

12. Yun, D.-Y.; Kang, Y.-G.; Yun, B.; Kim, E.-H.; Kim, M.; Park, J.S.; Lee, J.H.; Hong, Y.-S. Distinctive metabolism of flavonoid between cultivated and semiwild soybean unveiled through metabolomics approach. J. Agric. Food Chem. 2016, 64, 5773-5783. [CrossRef]

13. Zhao, S.; Park, C.H.; Li, X.; Kim, Y.B.; Yang, J.; Sung, G.B.; Park, N.I.; Kim, S.; Park, S.U. Accumulation of rutin and betulinic acid and expression of phenylpropanoid and triterpenoid biosynthetic genes in mulberry (Morus alba L.). J. Agric. Food Chem. 2015, 63, 8622-8630. [CrossRef] [PubMed]

14. Ekor, M. The growing use of herbal medicines: Issues relating to adverse reactions and challenges in monitoring safety. Front. Pharmacol. 2014, 4, 177. [CrossRef] [PubMed]

15. Gulzar, M.; Syed, S.B.; Khan, F.I.; Khan, P.; Ali, S.; Hasan, G.M.; Taneja, P.; Hassan, M.I. Elucidation of interaction mechanism of ellagic acid to the integrin linked kinase. Int. J. Biol. Macromol. 2019, 122, 1297-1304. [CrossRef]

16. Naz, H.; Tarique, M.; Khan, P.; Luqman, S.; Ahamad, S.; Islam, A.; Ahmad, F.; Hassan, M.I. Evidence of vanillin binding to CAMKIV explains the anti-cancer mechanism in human hepatic carcinoma and neuroblastoma cells. Mol. Cell. Biochem. 2018, 438, 35-45. [CrossRef]

17. Wang, H.; Oo Khor, T.; Shu, L.; Su, Z.-Y.; Fuentes, F.; Lee, J.-H.; Tony Kong, A.-N. Plants vs. cancer: A review on natural phytochemicals in preventing and treating cancers and their druggability. Anti-Cancer Agents Med. Chem. 2012, 12, 1281-1305. [CrossRef]

18. Gulzar, M.; Ali, S.; Khan, F.I.; Khan, P.; Taneja, P.; Hassan, M.I. Binding mechanism of caffeic acid and simvastatin to the integrin linked kinase for therapeutic implications: A comparative docking and MD simulation studies. J. Biomol. Struct. Dyn. 2019, 37, 4327-4337. [CrossRef]

19. Han, D.H.; Lee, M.J.; Kim, J.H. Antioxidant and apoptosis-inducing activities of ellagic acid. Anticancer Res. 2006, 26, 3601-3606.

20. Cho, Y.S.; Borland, M.; Brain, C.; Chen, C.H.T.; Cheng, H.; Chopra, R.; Chung, K.; Groarke, J.; He, G.; Hou, Y.; et al. 4-(Pyrazol-4-yl)-pyrimidines as Selective Inhibitors of Cyclin-Dependent Kinase 4/6. J. Med. Chem. 2010, 53, 7938-7957. [CrossRef]

21. Shamsi, A.; Ahmed, A.; Bano, B. Probing the interaction of anticancer drug temsirolimus with human serum albumin: Molecular docking and spectroscopic insight. J. Biomol. Struct. Dyn. 2018, 36, 1479-1489. [CrossRef] [PubMed]

22. Anand, U.; Jash, C.; Boddepalli, R.K.; Shrivastava, A.; Mukherjee, S. Exploring the mechanism of fluorescence quenching in proteins induced by tetracycline. J. Phys. Chem. 2011, 115, 6312-6320. [CrossRef] 
23. Shamsi, A.; Ahmed, A.; Khan, M.S.; Husain, F.M.; Amani, S.; Bano, B. Investigating the interaction of anticancer drug temsirolimus with human transferrin: Molecular docking and spectroscopic approach. J. Mol. Recognit. 2018, 31, e2728. [CrossRef] [PubMed]

24. Shamsi, A.; Mohammad, T.; Khan, M.S.; Shahwan, M.; Husain, F.M.; Rehman, M.; Hassan, M.; Ahmad, F.; Islam, A. Unraveling Binding Mechanism of Alzheimer's Drug Rivastigmine Tartrate with Human Transferrin: Molecular Docking and Multi-Spectroscopic Approach towards Neurodegenerative Diseases. Biomolecules 2019, 9, 495. [CrossRef] [PubMed]

25. Ross, P.D.; Subramanian, S. Thermodynamics of protein association reactions: Forces contributing to stability. Biochemistry 1981, 20, 3096-3102. [CrossRef]

26. Shamsi, A.; Al Shahwan, M.; Ahamad, S.; Hassan, M.I.; Ahmad, F.; Islam, A. Spectroscopic, calorimetric and molecular docking insight into the interaction of Alzheimer's drug donepezil with human transferrin: Implications of Alzheimer's drug. J. Biomol. Struct. Dyn. 2020, 38, 1094-1102. [CrossRef]

27. Watanabe, H.; Tanase, S.; Nakajou, K.; Maruyama, T.; Kragh-Hansen, U.; Otagiri, M. Role of Arg-410 and Tyr-411 in human serum albumin for ligand binding and esterase-like activity. Biochem. J. 2000, 349, 813-819. [CrossRef]

28. Aneja, B.; Queen, A.; Khan, P.; Shamsi, F.; Hussain, A.; Hasan, P.; Rizvi, M.M.A.; Daniliuc, C.G.; Alajmi, M.F.; Mohsin, M.; et al. Design, synthesis \& biological evaluation of ferulic acid-based small molecule inhibitors against tumor-associated carbonic anhydrase IX. Bioorg. Med. Chem. 2020, 115424. [CrossRef]

29. Dahiya, R.; Mohammad, T.; Gupta, P.; Haque, A.; Alajmi, M.F.; Hussain, A.; Hassan, M.I. Molecular interaction studies on ellagic acid for its anticancer potential targeting pyruvate dehydrogenase kinase 3. RSC Adv. 2019, 9, 23302-23315. [CrossRef]

30. Dahiya, R.; Mohammad, T.; Roy, S.; Anwar, S.; Gupta, P.; Haque, A.; Khan, P.; Kazim, S.N.; Islam, A.; Ahmad, F. Investigation of inhibitory potential of quercetin to the pyruvate dehydrogenase kinase 3: Towards implications in anticancer therapy. Int. J. Biol. Macromol. 2019. [CrossRef]

31. AAT Bioquest, Inc. Quest Graph ${ }^{\mathrm{TM}}$ IC50 Calculator; AAT Bioquest, Inc.: Sunnyvale, CA, USA, 2019; Available online: https://www.aatbio.com/tools/ic50-calculator (accessed on 13 May 2020).

32. Wolff, A.C. CDK4 and CDK6 inhibition in breast cancer-A new standard. Mass Med. Soc. 2016. [CrossRef]

33. Pernas, S.; Tolaney, S.M.; Winer, E.P.; Goel, S. CDK4/6 inhibition in breast cancer: Current practice and future directions. Ther. Adv. Med. Oncol. 2018, 10, 1758835918786451. [CrossRef] [PubMed]

34. Ojala, P.M.; Yamamoto, K.; Castanos-Velez, E.; Biberfeld, P.; Korsmeyer, S.J.; Makela, T.P. The apoptotic v-cyclinCDK6 complex phosphorylates and inactivates Bcl-2. Nat. Cell Biol. 2000, 2, 819-825. [CrossRef] [PubMed]

35. McCubrey, J.A.; Steelman, L.S.; Chappell, W.H.; Abrams, S.L.; Wong, E.W.; Chang, F.; Lehmann, B.; Terrian, D.M.; Milella, M.; Tafuri, A. Roles of the Raf/MEK/ERK pathway in cell growth, malignant transformation and drug resistance. Biochim. Biophys. Acta (Bba)-Mol. Cell Res. 2007, 1773, 1263-1284. [CrossRef] [PubMed]

36. Sever, R.; Brugge, J.S. Signal transduction in cancer. Cold Spring Harb. Perspect. Med. 2015, 5, a006098. [CrossRef]

37. Gross, S.; Rahal, R.; Stransky, N.; Lengauer, C.; Hoeflich, K.P. Targeting cancer with kinase inhibitors. J. Clin. Investig. 2015, 125, 1780-1789. [CrossRef] [PubMed]

38. Khan, P.; Rahman, S.; Queen, A.; Manzoor, S.; Naz, F.; Hasan, G.M.; Luqman, S.; Kim, J.; Islam, A.; Ahmad, F. Elucidation of dietary polyphenolics as potential inhibitor of microtubule affinity regulating kinase $4:$ In silico and in vitro studies. Sci. Rep. 2017, 7,1-15. [CrossRef]

39. Gupta, P.; Mohammad, T.; Dahiya, R.; Roy, S.; Noman, O.M.A.; Alajmi, M.F.; Hussain, A.; Hassan, M.I. Evaluation of binding and inhibition mechanism of dietary phytochemicals with sphingosine kinase 1 : Towards targeted anticancer therapy. Sci. Rep. 2019, 9, 1-15. [CrossRef]

40. Naz, H.; Khan, P.; Tarique, M.; Rahman, S.; Meena, A.; Ahamad, S.; Luqman, S.; Islam, A.; Ahmad, F.; Hassan, M.I. Binding studies and biological evaluation of beta-carotene as a potential inhibitor of human calcium/calmodulin-dependent protein kinase IV. Int. J. Biol. Macromol. 2017, 96, 161-170. [CrossRef]

41. Kaul, R.; Risinger, A.L.; Mooberry, S.L. Microtubule-Targeting Drugs: More than Antimitotics. J. Nat. Prod. 2019, 82, 680-685. [CrossRef]

42. Domitrović, R.; Škoda, M.; Marchesi, V.V.; Cvijanović, O.; Pugel, E.P.; Štefan, M.B. Rosmarinic acid ameliorates acute liver damage and fibrogenesis in carbon tetrachloride-intoxicated mice. Food Chem. Toxicol. 2013, 51, 370-378. [CrossRef] [PubMed] 
43. Chu, X.; Ci, X.; He, J.; Jiang, L.; Wei, M.; Cao, Q.; Guan, M.; Xie, X.; Deng, X. Effects of a natural prolyl oligopeptidase inhibitor, rosmarinic acid, on lipopolysaccharide-induced acute lung injury in mice. Molecules 2012, 17, 3586-3598. [CrossRef] [PubMed]

44. Gupta, P.; Mohammad, T.; Khan, P.; Alajmi, M.F.; Hussain, A.; Rehman, M.T.; Hassan, M.I. Evaluation of ellagic acid as an inhibitor of sphingosine kinase 1: A targeted approach towards anticancer therapy. Biomed. Pharmacother. 2019, 118, 109245. [CrossRef] [PubMed]

45. Liu, Q.; Liang, X.; Niu, C.; Wang, X. Ellagic acid promotes A549 cell apoptosis via regulating the phosphoinositide 3-kinase/protein kinase B pathway. Exp. Ther. Med. 2018, 16, 347-352. [CrossRef]

46. Khan, P.; Idrees, D.; Moxley, M.A.; Corbett, J.A.; Ahmad, F.; von Figura, G.; Sly, W.S.; Waheed, A.; Hassan, M.I. Luminol-based chemiluminescent signals: Clinical and non-clinical application and future uses. Appl. Biochem. Biotechnol. 2014, 173, 333-355. [CrossRef]

47. Jacobson, M.P.; Pincus, D.L.; Rapp, C.S.; Day, T.J.F.; Honig, B.; Shaw, D.E.; Friesner, R.A. A hierarchical approach to all-atom protein loop prediction. Proteins Struct. Funct. Bioinform. 2004, 55, 351-367. [CrossRef]

48. Jacobson, M.P.; Friesner, R.A.; Xiang, Z.; Honig, B. On the Role of the Crystal Environment in Determining Protein Side-chain Conformations. J. Mol. Biol. 2002, 320, 597-608. [CrossRef]

49. Bochevarov, A.D.; Harder, E.; Hughes, T.F.; Greenwood, J.R.; Braden, D.A.; Philipp, D.M.; Rinaldo, D.; Halls, M.D.; Zhang, J.; Friesner, R.A. Jaguar: A high-performance quantum chemistry software program with strengths in life and materials sciences. Int. J. Quantum Chem. 2013, 113, 2110-2142. [CrossRef]

50. Morris, G.M.; Huey, R.; Lindstrom, W.; Sanner, M.F.; Belew, R.K.; Goodsell, D.S.; Olson, A.J. AutoDock4 and AutoDockTools4: Automated docking with selective receptor flexibility. J. Comput. Chem. 2009, 30, 2785-2791. [CrossRef]

51. Neudert, G.; Klebe, G. DSX: A knowledge-based scoring function for the assessment of protein-ligand complexes. J. Chem. Inf. Model. 2011, 51, 2731-2745. [CrossRef]

52. Pronk, S.; Pall, S.; Schulz, R.; Larsson, P.; Bjelkmar, P.; Apostolov, R.; Shirts, M.R.; Smith, J.C.; Kasson, P.M.; van der Spoel, D.; et al. GROMACS 4.5: A high-throughput and highly parallel open source molecular simulation toolkit. Bioinformatics 2013, 29, 845-854. [CrossRef] [PubMed]

53. Schuttelkopf, A.W.; van Aalten, D.M. PRODRG: A tool for high-throughput crystallography of protein-ligand complexes. Acta Cryst. D Biol. Cryst. 2004, 60, 1355-1363. [CrossRef]

54. Frisch, M.J.; Trucks, G.W.; Schlegel, H.B.; Scuseria, G.E.; Robb, M.A.; Cheeseman, J.R.; Scalmani, G.; Barone, V.; Mennucci, B.; Petersson, G.A.; et al. Gaussian 09; Gaussian, Inc.: Wallingford, CT, USA, 2009.

55. Zielkiewicz, J. Structural properties of water: Comparison of the SPC, SPCE, TIP4P, and TIP5P models of water. J. Chem. Phys. 2005, 123, 104501. [CrossRef] [PubMed]

56. Kumari, R.; Kumar, R.; Lynn, A. g_mmpbsa-A GROMACS tool for high-throughput MM-PBSA calculations. J. Chem. Inf. Model. 2014, 54, 1951-1962. [CrossRef] [PubMed]

57. Gupta, P.; Khan, F.I.; Roy, S.; Anwar, S.; Dahiya, R.; Alajmi, M.F.; Hussain, A.; Rehman, M.T.; Lai, D.; Hassan, M.I. Functional implications of $\mathrm{pH}$-induced conformational changes in the Sphingosine kinase 1. Spectrochim. Acta A Mol. Biomol. Spectrosc. 2020, 225, 117453. [CrossRef] [PubMed]

58. Chi, Z.; Liu, R. Phenotypic characterization of the binding of tetracycline to human serum albumin. Biomacromolecules 2010, 12, 203-209. [CrossRef]

59. Naz, H.; Jameel, E.; Hoda, N.; Shandilya, A.; Khan, P.; Islam, A.; Ahmad, F.; Jayaram, B.; Hassan, M.I. Structure guided design of potential inhibitors of human calcium-calmodulin dependent protein kinase IV containing pyrimidine scaffold. Bioorg. Med. Chem. Lett. 2016, 26, 782-788. [CrossRef]

60. Shamsi, F.; Hasan, P.; Queen, A.; Hussain, A.; Khan, P.; Zeya, B.; King, H.M.; Rana, S.; Garrison, J.; Alajmi, M.F.; et al. Synthesis and SAR studies of novel 1,2,4-oxadiazole-sulfonamide based compounds as potential anticancer agents for colorectal cancer therapy. Bioorg. Chem. 2020, 98, 103754. [CrossRef]

61. Khan, P.; Queen, A.; Mohammad, T.; Smita; Khan, N.S.; Hafeez, Z.B.; Hassan, M.I.; Ali, S. Identification of $\alpha$-Mangostin as a Potential Inhibitor of Microtubule Affinity Regulating Kinase 4. J. Nat. Prod. 2019, 82, 2252-2261. [CrossRef]

(C) 2020 by the authors. Licensee MDPI, Basel, Switzerland. This article is an open access article distributed under the terms and conditions of the Creative Commons Attribution (CC BY) license (http://creativecommons.org/licenses/by/4.0/). 